\title{
A Critical Analysis of Empiricism
}

\author{
F. M. Anayet Hossain \\ Department of Philosophy, University of Chittagong, Chittagong, Bangladesh \\ Email: fmhossain77@yahoo.com
}

Received 26 May 2014; revised 30 June 2014; accepted 11 July 2014

Copyright (C) 2014 by author and Scientific Research Publishing Inc.

This work is licensed under the Creative Commons Attribution International License (CC BY).

http://creativecommons.org/licenses/by/4.0/

(c) (i) Open Access

\section{Abstract}

Empiricism is a philosophical theory which argues that human knowledge is derived entirely from sensory experience. As a branch of epistemology, empiricism disregards the concept of instinctive ideas and focuses entirely on experience and evidence as it relates to sensory perception. Empiricism is a philosophical school holding that knowledge can only be (or is primarily) gained from sensory experience. Accordingly, it rejects any (or much) use of a priori reasoning in the gathering and analysis of knowledge. It rivals rationalism according to which reason is the ultimate source of knowledge. The philosophy of empiricism was first put forth in John Locke's An Essay Concerning Human Understanding. Locke argued that the only way by which human acquire knowledge is through experience. Locke firmly argued that humans are incapable of formulating or possessing inherent ideas. The aim of this paper is to explain that the traditional empiricist standpoint in the fields of epistemology and then try to show that it is not adequate for explaining some things relevant to these fields. For that the traditional empiricist methods needs to be supplemented by extra-logical principles that are not strictly empirical.

\section{Keywords}

\section{Empiricism, Skepticism, Generalizations}

\section{Introduction}

In the realm of philosophy, empiricism arises as one of the theories regarding the sources of knowledge. As an epistemological problem, it persists among the philosophers from the past down to the present. In any philosophical discussion the world "knowledge" occupies a very important, rather the central place. The problem of the nature of knowledge has been a central one in philosophy almost from the earliest times of its history (Edwards, 1967). Before trying to know about things philosophy finds it indispensible to undertake a consideration of the nature and possibility of knowledge. What is knowledge? How do we get knowledge? What are the sources of knowledge? Through questions like these and many similar ones many renowned philosophers dis- 
cussed the nature of knowledge in various ways from different perspectives. But even to-date, they could not come to any common consensus about this matter.

Empiricism is perhaps as old as philosophy itself but it did not come to flourish in philosophy before the seventeenth century of the Christian era except only for a brief while at the time of the sophists of the early Greek Period (Brightman, 1954). At the beginning of the modern age, a number of eminent philosophers increasingly applied the empiricist method in philosophical investigations. Through the works of thinkers like Locke, Berkley and Hume during the seventeenth and eighteenth centuries empiricism came to establish itself as a definite and vigorous creed in philosophy (Matin, 1968). According to empiricists, experience provides the marks of criteria of knowledge and these criteria may be subsequently used to determine the extent of our knowledge.

\section{Empiricism and Its Limitation}

This paper will discussed throw some lights on the limits of modern empiricism. A critical analysis of modern empiricism especially the Humeans and Kantians shows that it culminates in scepticism, Subjectivism and agnosticism. The crisis of modern empiricism is that the logical culmination of these phases of modern empiricism denies the existence of objective reality. It also ignores the dialectical relationship of the subjective and objective factors of knowledge. Traditional empiricists emphasized that, sense experience is the only guide in our understanding of the world; that it is the only method and criterion of knowledge and truth. This opinion or judgment cannot be established on the evidence of experience, is to be treated as uncertain, false or even superstitions, no ideas are there that are not tractable in terms of sense experience. According to them all concepts, all knowledge and all scientific generalizations are ultimately reducible to sensations and perceptions (Hospers, 1967).

"Man is the measure of all things"- the ancient Greek sophists may be termed as the fore runner of the modern empiricists, particularly of Locke's "mind" as the "Tabula rasa" (Locke, 1959). To my mind, both the sophists and the modern empiricists have laid great emphasis on the sense experiences of man as a source of his knowledge of life and world. According to them, man derives knowledge through the five sense experiences likely sight, hearing, smell touch ad taste. Of course, one may distinguish between direct and indirect experience.

Direct experience means that one gets acquainted with an object himself or herself though a physical contact with the object, such as A smells the rose, $\mathrm{D}$ touches the table and $\mathrm{Z}$ hears a sound. On the other hand, indirect experience gets that the subject is personally involved in the knowledge process. He or she gets knowledge about the object hearing from some person or reading a book. Direct or indirect experiences do not however, make any essential difference in so far as the means through which knowledge is acquired.

\subsection{Perception Is the Only Source of Knowledge}

As a theory of knowledge empiricism upholds the view that experience is the only source of knowledge, or that senses alone can provide us with knowledge. This form of empiricism can be refuted only by one who has such a conception that senses alone can provide us with knowledge. The common-sense view is that, the senses do provide us with knowledge of some sort and most of the people adopt this kind of empirical view. According to Hume, if unknown matters of fact are concerned, one does not know of any belief that could be called reasonable (Hume, 1960). Induction and knowledge are our strongest beliefs. We never can give them up. But their creditability cannot be proved to be rational. As they have no basis of experience, their truth can never be necessarily established. For Hume if necessity has a meaning it must be translatable into observable relationships. Thus Hume's philosophy ends with the thesis that no knowledge is possible and no science is possible (Hume, 1902). Hume denies the logical justification of inductive reasoning. According to him, if we accept the arguments based on past experience as the standard of our future judgments then it would be probable only. He claims that, arguments concerning existence are founded on the relation of cause and effect. The relation, he says, is only probable not necessary. Inductive leap, for Hume is nothing but an inference of one proposition from the other; to say that it is experimental is begging the question.

A. J. Ayer holds that, one cannot be absolutely sure about what one knows. Necessity is knowledge is to be found in a limited sense. What is known must be true, but that truth is not a necessary truth. We know matters of fact as a true as far as; it is possible on our part to establish them as true. Ayer thus holds that absolute necessity cannot be obtained in knowledge, but scientific knowledge is definitely true. It is not rational to discuss that knowledge of science as true as they are absolutely necessary (Ayer, 1964). 
Like Hume, the empiricism of Russell also results in skepticism. It becomes clear when he raises the question: "Is there any knowledge in the world which is so certain that no reasonable man could doubt it? Russell gets straight into the problem of justification i.e. whether there is any justification of drawing inferences from past sense data. According to Russell's view all knowledge is in some degree doubtful and we cannot say what degree of doubtfulness makes it to be knowledge (Yudin, 1967). He points out that all particular facts that are known without inference are facts known by perception or memory, that is to say, through experience. In this respect the empiricist's principle calls for no limitation. But our knowledge is not confined to perception or memory alone (Russell, 1961). We admit the validity of scientific knowledge which is based on generalizations from experience. Inferential knowledge or induction cannot be supported by experience only. Induction needs the support of some extra-logical general principles that are not based upon experience. The causal principle and the law of uniformity of nature must supplement experience to make induction possible. And this, According to Russell, shows that empiricism as a theory of knowledge is inadequate.

According to Russell, we are acquainted with our sense-data and probably with ourselves. Induction, for him, is to draw inferences from these sense-data. For example, "The sun will rise tomorrow" this statement is inferred from the past sense-data, which is not certain, rather probable only. Russell says that, still there remains a probability that "The sun may not rise tomorrow." So drawing inferences from past sense-data is only probable. There, by denying the certainty of scientific knowledge (cause effect relationship) both Hume and Russell have opened the door for skepticism (Hudson, 1991).

Immanuel Kant has of course, told in his Critique of Pure Reason that every knowledge begins with experience both apriori and a posteriori knowledge but not all knowledge arises out of experience, only a posteriori knowledge arises out of experience; and there is also an apriori knowledge of the world which occurs through a perception of the nature of the thing about which the statement is made. In one case we deal with a posteriori knowledge and in the other, with apriori knowledge. In one case knowledge arises out of experience, in the other experience is only the occasion for my coming to know (Kant, 1965).

Although Kant made a historic attempt to synthesize empiricism and rationalism, the empiricist do not accept that arithmetical, geometrical, logical and ethical judgments are completely apriori. Can anyone have an insight or knowledge through intellect or reason that $3+3=6$ unless one did not have similar experiences in the past? Can one conclude that all circles are round if one would have noticed an exception to it? Because we have always seen that things having shapes have always sizes we can, with the help of reason, make the judgment that a thing that has a shape has a size. Similarly, consequences of unnecessary infliction of pains were found to be evil in the previous occasions, and hence the conclusion is: unnecessary infliction of pain is evil.

\subsection{Some Traditional Empiricist Views}

Traditional empiricism gives exclusive importance to experience and emphasizes that metaphysics is impossible. Kant and many others accept this view about metaphysics. Kant does not uphold the empiricist theory of knowledge (Kant, 1965). Nevertheless, his conception of metaphysics is very much similar to that of Hume. According to both of them metaphysics as the science of supra-sensible reality is impossibility. But of thought that logical positivists try to show that metaphysics as the attempt to demonstrate that there are entities which lie beyond the reach of any possible experience is a non-sensible effort. According to the logical positivists the meaning of a proposition lies in its verifiability (Hempel, 1966). Metaphysics makes references to entities which are not accessible to observation, that is, which cannot be verified by experience.

There is much about which the rationalist and the empiricist are in agreement. The important question however is: Are there any synthetic a priori statements? The rationalists say there are while the empiricist says there are not. This is the controversial issue. With respect to this question rationalism and empiricism are mutually exclusive and exhaustive alternatives. This means that one must be either a rationalist or an empiricist but cannot be both (Edwards, 1967).

An empiricist believes that, 1) all a priori statements are analytic and 2) all synthetic statements are a posteriori. Of course, empiricists disagree among themselves as to which of these two categories a given statement belongs to. The rationalist, while accepting only the converses of these two statements as true, believes that it is possible to break these pairs. Rationalists may not all agree among themselves on which truths are synthetic and a priori, but anyone who holds that there is even one synthetic a priori truth is a rationalist. It is up to the rationalist to produce examples of synthetic a priori truth (Ayer, 1964). On the other hand, it is up to the empiricist to 
show that the examples given by the rationalist are not examples of synthetic a priori truths. The empiricist may do this in either of two ways. Given any alleged example, he may show that:

1) If it is a priori, then it is not synthetic but analytic; or

2) If it is synthetic, then it is not a priori but a posteriori (Ayer, 1964).

The function of philosophy would then be just to analyze objects into atomic facts. A comprehensive view of the whole universe as really a structure of elementary entities would be a metaphysical non-sense. Although Carnap and Ayer who led the two camps to logical positivism discuss the conception that empirical knowledge free from any risk or error can ever be established. They however reject the skeptic stand on induction and give a new meaning to knowledge, science and metaphysics (Odegard, 1982).

Experience is a comprehensive term and it has various dimensions. Experience essentially means a closer type of contract of the knower with the object known. Experience is an object or thing makes us understand with the thing or object is; it qualifies the object with some attributes. Speaking a bit differently, the 'this' and the 'that' of an object become meaningful to the knower through a medium which we call meaningful to the knower through a medium, which we call the experience of the object (Russell, 1912). Experiences, thus results, in knowledge and understanding of those things and objects about which we have the experience. Experience a conscious awareness of something; it may mean all the data and processes of consciousness.

\subsection{Sense Perception Is Consistent with Reality}

Accepting sense perceptions to be the source of knowledge, agnostics hold that knowledge is true, in so far as sense perceptions are consistent with reality, but false if it is inconsistent. Hume opines that: The mind has never anything present to it but the perceptions and cannot possibly reach any experience of their connection with objects (Hume, 1966). Although Hume is an idealist his theory of sense perceptions denies the existence of God. This aspect of Hume's agnosticism at first appealed to some scientists because it was spearheaded against theology. The agnostics deny the existence of the material world and the possibility of cognition. They also reduce all knowledge to sense perception. They are unable to explain how certain ideas and concepts irreducible to sensuous images and sensations.

It is very clear that, traditional empiricism has got its own limits. We cannot doubt the empiricist view that we have no formal justification of induction. But that does not disprove induction. Ayer rightly points to the fact that for induction there is not better argument than induction itself (Ayer, 1946). For both our knowledge of the past and our knowledge of the other minds rest on inductive reasoning. He says that, it is logically impossible for us to have direct knowledge either the past or other people's experiences. In both cases our knowledge rests on inferences from what we observe. Our knowledge about the past rests on our observation of what is now happening-inferences about the past being in this respect parallel to predictive about the future; our knowledge of other people's experiences rests on our observation of the displays of feelings in the behavior of other people (Steven, 1970).

It is logically possible that our statements about the past are mistaken and it is logically possible that other people have no mind; but all the same we can rightly and reasonably claim to be sure about a particular event of the past or a present feeling of our dear and near ones (Passmore, 1932). Strict adherences to the empiricist principle that induction is not possible complete us to burn metaphysics along with science. This is why; now-a-days traditional empiricism has got no place in philosophical circle. Empiricism in the moderated sense of Ayer, Russell and others establishes knowledge, science and metaphysics as possible.

\subsection{Empiricism Led to Subjectivism}

Empiricism ultimately leads to subjectivism, which not only denies the independent existence of subjective reality, but also completely ignores the dialectical relationship between the subjective and objective factors of knowledge. It cannot see how the objective enriches the subjective (Passmore, 1932). It ignores the dialectical character of subject-object relationship. Empiricism would deprive philosophy of any kind of pursuit for knowing the "reality". It would only analyze objects and leave the study of the reality (Lenin, 1967). But it is very much necessary to have some knowledge of the whole when we try to know the parts analytically. An empiricist may still insist that the statement is a posteriori in the sense that it is known on the basis of experience and what we have to await the verdict of experience to ascertain whether the statement holds true or false (Hospers, 1967). In this case the empiricist must hold that the statement may be either true or false. But perhaps few people will 
accept this view. Even a skeptic who is in doubt as to whether the sun will rise in the east. It will not likely to deny that our statement is necessarily true. We have tried to show how in our day to day reasoning we unconsciously take synthetic a priori statements for granted without being aware of it. If empiricism is correct no statement which has a factual content can be necessary or certain. Consequently, there are two ways of dealing with the truths of logic and mathematics which are open to the empiricist. Like all empirical hypotheses, the truths of logic and mathematics were theoretically fallible. Being inductive generalizations they were not certain but only highly probable, and the difference between them and the hypotheses of natural science was a difference in degree and not in kind, according to Mills' view.

\section{Conclusion}

Moreover, empiricism is not to be totally accepted because it presumes that the world falls apart into two classes of entities. Firstly, "subjects" whose principal task is to perceive and secondly, "objects" which are only to be perceived. But this whole idea is defective. If there is a sharp distinction between the subject and the object, there could never be any link which could possibly connect substances so disparate. For example, a spiritual substance could ever perceive an external world. This is why the neutral monists, the supporters of the identity theory, Strawson and others reject the idea that body and mind are substantially disparate (Ayer, 1964). Neutral monism upholds the view that there is no metaphysical dualism of body and mind, but only a structural difference between them as both are made of the same elementary stuff. The traditional empiricist view that our status in the world is like that of a spectator or a looker-on. They hold that the world is phenomenological revealed to the human being as his world, not in the sense of being the world which he perceives but as being the world he cares about made up of things which are hindrances or helps (Brightman, 1954). Through a detailed discussion or critical examination of the theories mentioned above, knowledge includes a dialectical unity of the subject and the object. The subjective is the product of the development of the material world. The subjective comprises an objective content in as much as it reflects objective reality. The existence of the subjective is an objective fact, independent of man's consciousness. Consequently, even the objective is above all a reality independent of the subject and the fact that for the subject it exists only in so far as the subject exists, is not a condition of its own existence. Empiricism in the traditional sense cannot meet the demands of enquiries in the fields of epistemology and metaphysics because of its inherent limitations. Empiricism cannot provide us with the certainty of scientific knowledge in the sense that it denies the existence of objective reality, ignores the dialectical relationship of the subjective and objective contents of knowledge.

\section{References}

Ayer, A. J. (1964a). Foundation of Empirical Knowledge (pp. 66-69, 71, 88-93). London: Macmillan and Co. Ltd.

Ayer, A. J. (1964b). The Problem of Knowledge (pp. 55-64). Harmondsworth: Penguin Books.

Ayer, A. J. (1946). Language, Truth and Logic (2nd ed., pp. 59-63). London: Victor-Gollancez Ltd.

Brightman, S. B. (1954). A Philosophy of Religion (pp. 19-23, 65-78). New York: Prentic Hall.

Edwards, P. (Ed.) (1967). The Encyclopedia of Philosophy (pp. 19, 341-346). New York: The Macmillan Company.

Hempel, C. G. (1966). Philosophy of Natural Science (p. 66). London: Printing Hall.

Hospers, J. (1967). An Introduction to Philosophical Analysis (pp. 65-78, 117-126). London: Printing Hall.

Hudson, W. D. (1991). Modern Moral Philosophy (p. 69). London: Macmillian Education Ltd.

Hume, D. (ed.) (1960). A Treatise of Human Nature (pp. 47-63). New York: Oxford University Press.

Hume, D. (1902). An Enquires Concerning the Human Understanding (pp. 54-59). Oxford: Oxford University Press.

Hume, D. (1966). Enquires Concerning the Human Understanding and Concerning the Principles of Morals (pp. 160-163). London: Oxford University Press.

Kant, I. (1965). Critique of Pure Reason (Translated by N. K. Smith, pp. 11, 40-43). New York: St. Martin’s Press.

Lenin, V. I. (1967). Materialism and Empirio-Criticism (p. 17). Peking: Foreign Languages Press.

Locke, J. (1959). An Essay Concerning Human Understanding (Vol. ii, pp. 122-126). New York: Dover Publications.

Matin, A. (1968). An Outline of Philosophy (pp. 33-47). Dhaka: Mullick Brothers.

Odegard, D. (1982). Knowledge and Scepticism (p. 129). New Jersey: Rowman and Littlefield,.

Passmore, J. (1932). A Hundred Years of Philosophy (pp. 179, 390). New York: Free Press. 
Russell, B. (1961). An Outline of Philosophy (p. 45). London: George Allen \& Unwind Ltd.

Russell, B. (1912). The Problems of Philosophy (pp. 109-115). London: Oxford University Press.

Steven, M. (1970). The Philosophical Foundations of Education (p. 127). New York: Hapner \& Row.

Yudin, P. (1967). A Dictionary of Philosophy (pp. 111-116). Moscow: Progress Publishers. 
Scientific Research Publishing (SCIRP) is one of the largest Open Access journal publishers. It is currently publishing more than 200 open access, online, peer-reviewed journals covering a wide range of academic disciplines. SCIRP serves the worldwide academic communities and contributes to the progress and application of science with its publication.

Other selected journals from SCIRP are listed as below. Submit your manuscript to us via either submit@scirp.org or Online Submission Portal.
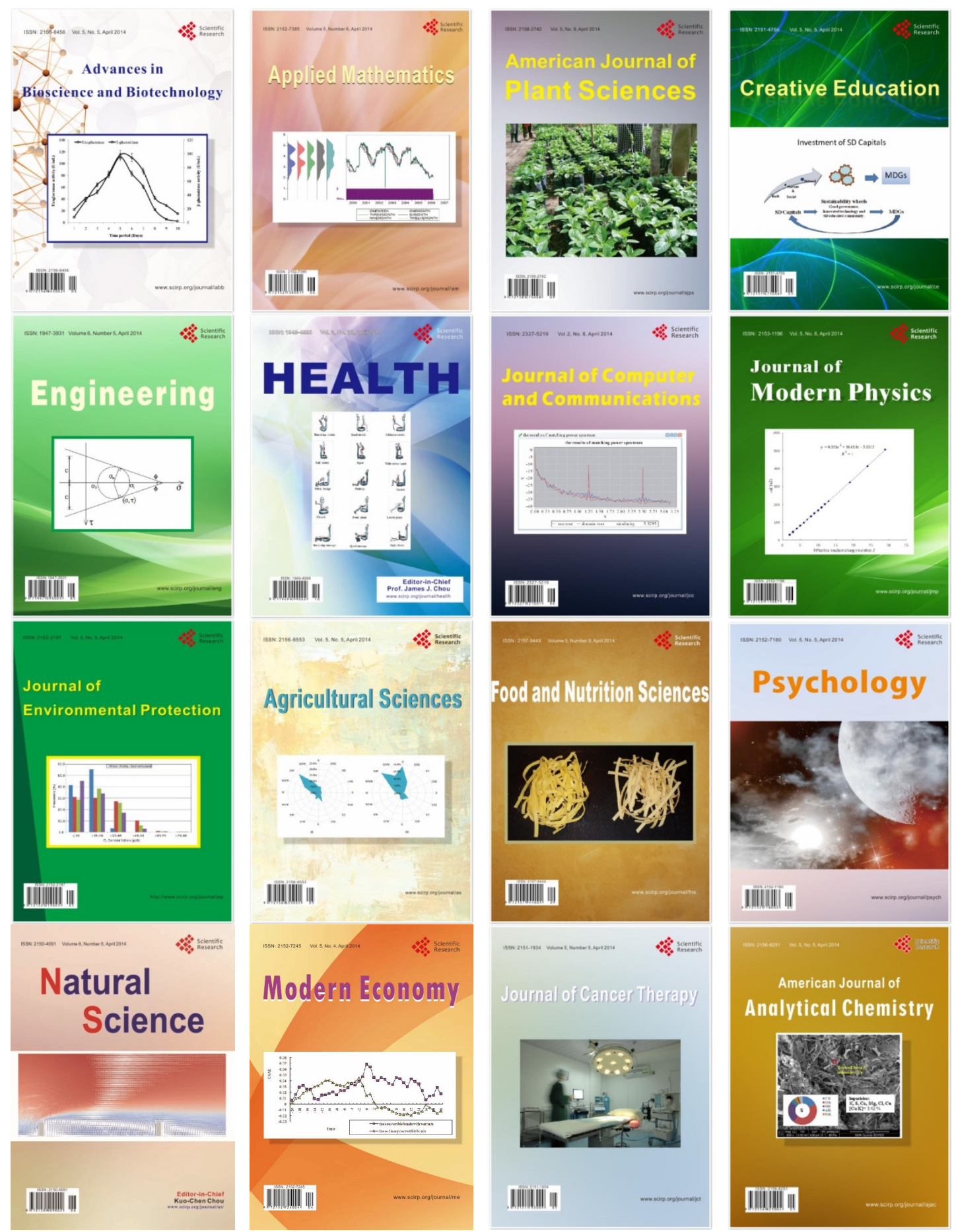